\title{
The Influence of Environmental Concern and Purchase Intent in Buying Green Products
}

\author{
Sergio Silva Braga Junior ${ }^{1}$, Dirceu da Silva², \\ Marcelo Luiz D. S. Gabriel'2, Waleska Reali de Oliveira Braga ${ }^{1}$ \\ 1 University Estadual Paulista (UNESP), Brazil \\ 2 Nine of July University (UNINOVE), Brazil \\ sergio@tupa.unesp.br, dirceuds@uninove.br, \\ mgabriel.br@gmail.com, waleskareali@gmail.com
}

\begin{abstract}
Current analysis evaluates the influence of environmental concern in people's retail buying behavior of green products. The purpose was to assess whether the consumer is recognizing and effectively declaring that buying green products in retail. Given the purpose, an exploratory study was conducted quantitative nature through a survey with a sample of 811 respondents. As a result, there is a possibility the consumer does not realize the importance of changing the habit of consumption, more fixed in their routine to buy and past experience you have that attitude strengthens the fact suffer a low influence his behavior.
\end{abstract}

Keywords: Green consumption; purchase intention; green products; retail

eISSN 2398-4295 @ 2018. The Authors. Published for AMER ABRA cE-Bs by e-International Publishing House, Ltd., UK. This is an open-access article under the CC BY-NC-ND license (http://creativecommons.org/licenses/by$n c-n d / 4.0 /$ ). Peer-review under responsibility of AMER (Association of Malaysian Environment-Behaviour Researchers), ABRA (Association of Behavioural Researchers on Asians) and cE-Bs (Centre for EnvironmentBehaviour Studies), Faculty of Architecture, Planning \& Surveying, Universiti Teknologi MARA, Malaysia.

DOI: http://dx.doi.org/10.21834/ajbes.v3i12.134 


\subsection{Introduction}

Issues of environmental concern are gaining more and more space in business and academia. This movement is due to the emergence of the concern that hit the industry, retailers and consumers about the impact of the current consumerism of modern society. To Crumpei, Boncu e Crumpei (2014) values, beliefs and personal ethics are motivator's ingredients to determine people's actions on environmental concern.

Even so, people have shown that the fact that environmental concern does not mean that green consumption necessarily happen, as has been shown by some studies linking environmental concerns with the purchase of green products (Braga Junior \& Silva, 2013). This can be explained by Bagozzi (1981) where the relationship of behavior and attitude is indirect and must have as a mediator purchase intent to transform something specific.

Thus, the research problem that guides the work can be expressed by the following question: Do environmental concerns influence the purchase of green products at retail? In this sense, the objective was to assess whether the consumer is recognizing and effectively declaring that buying green products in retail.

The hypotheses emerged from the literature and indicate that the behavior generates the intention, and this generates the attitude of consumers to purchase products at retail. The research model was mounted on this structure and considered the environmental concern as behavior, purchase intent and purchase declared as attitude. Given the purpose, an exploratory study was conducted quantitative nature through a survey with a sample of 811 respondents.

The present study demonstrated that environmental concern and intention to purchase the exhibit strong relationship and the focus should be to get an attitude. Moreover, the results demonstrate the fact that opinion is on the correct path, but suffer from the great influence of politically correct answers and end up damaging future developments in new research. This reinforces the idea of social desirability, where people answer the research of politically correct manner.

\subsection{Literature Review}

\subsection{Green Products}

The concern in differentiating aspects that define a green product of the conventional product has been the subject of study in several research (Manuela et. al., 2013; Ar, 2012; Braga Junior et al, 2014; Luchs, Naylor, Irwin \& Raghunathan, 2010). Major retailers are presenting product launches that have a distinctive design, a larger volume or less packaging with the purpose of serving the green and sustainable appeal.

To differentiate conventional products of green products is important to know that green products are products not regarded as harmful to the environment and human health in both its content and in its packaging (Jacobi, 2006).

Thus, green product can be considered one that fulfills the same functions as the equivalent conventional product causing less damage to the environment throughout its life cycle and its composition does not harm or assaults unless the environment as well as use 
or no packaging. However, it should also bring in its concept ecological, political dimensions, capacity for social response and fair trade.

It can be noticed that consumers of green products do not only choose the products for your green appeal, but also by the benefit they offer (Morh, Webb, 2005). While no consumer product has zero impact on the environment, the term "green product" is used for products that strive to protect or improve the environment, conserve energy and / or natural resources and to reduce or eliminate the use of agent toxic pollutants and waste. This fact makes the studies in the field nearest the traditional lines of consumer behavior as overcharging take ethical and environmental appeal of these products.

A decisive factor for understanding this process is to accept that individuals often consider values that they, in fact, do not have to make a purchase decision.

Even without confirming the enhancement of ethical and environmental aspects of the consumer and the prevalence of cognitive aspects in the purchase decision, companies are betting on green products market by focusing your marketing efforts precisely on cognitive aspects. This is a point that demonstrates, increasingly, the growth of green consumption and the fact that companies are investing in products that cater to this market aspects.

\subsection{Intention, Attitude And Social Desirability}

About the preference and choice opportunities, choice opportunities are often directly observable, on the other hand; preferences are given the variations in behavior as opportunities arise as observed by Ozguven (2012).

Their influence of first and second order factors that affect the behavior and that depending on the time and situation, the individual may be more or less influenced and thus redeem certain memories already tried. This statement was reinforced by Bagozzi (1981) and Ajzen (2001) demonstrating that the intent and consequent behavior are strongly influenced by earlier experiences (attitudes).

Tai et. al. (2012) examined how is constructed purchase intent for buying groups, Jamaluddim et. al. (2013) on the effect of brand and Yildirim and Aydin (2012) in the purchase decision of the effects of discount announcements, thus demonstrating the influence of consumer's purchase intent.

According to Bagozzi (1981), attitudes will only affect the behavior through behavioral intentions, or rather, intentions directly affect behavior and only indirectly attitudes affect consumers' behavior.

According to Ajzen (2001) attitudes are the achievements related to some aspect of the world around the individual and represent your evaluation of this aspect in question. Attitude measurements are the activities that consumers decide to take in their behavior purchasing in retail supermarkets.

Ajzen (2001) explains that there is a general agreement that an attitude represents a quick evaluation of a psychological object caught in attribute dimensions as something goodbad, dangerous-beneficent, pleasant-unpleasant and sympathetic-antipathetic. The above author explains further that an attitude facilitates the adaptation of the subjects to the social environment in which they are inserted so that they express and defend their behavior and adequate themselves to it. 
However, there is a possibility that people who respond to surveys are presenting a politically correct behavior towards society and, thus, creating an error analysis of the results. This trend of correct behavior is called social desirability causing the individual hold themselves look good according to current cultural norms (Sârbescu et. al., 2012; RahimOf, 2011).

According to Poinhos et. al. (2008), social desirability corresponds to the trend to transmit a culturally acceptable image and according to social norms, with approval and avoidance of criticism in test situations.

Subjects with high social desirability will be more prone to provide answers that they consider better accepted by society regardless of their status as true or false, denying personal association to socially disapproved opinions or behaviors.

Ribas Junior et al. (2004, p. 84), social desirability is "the trend of people participating in psychological research to answer questions based". Respondents are inclined to give answers that they think socially more acceptable and correct even though such replies are against their attitudes, or rather, their true inclinations remain covert if they are not socially acceptable. The term 'social desirability' may also indicate answers given for the sake to pleasing the interviewer (RahimOf, 2011).

The theory of social desirability explains that politically correct cultural norms and standards affect subjects' answers especially in research that foments self-report, such as personality or psychological content research (Sârbescu et. al., 2012).

A response influence is extant when social and cultural standards affect the subjects' answers. It may be defined as a trend perspective to provide positive answers, or rather, answering positively when questioned, or giving negative answers (always answer negatively), according to Poinhos et. al. (2008).

Distortions caused by social desirability may also be related to other variables and subjective characteristics, such as the humor and self-perception. Self-deceit may occur within a research. According to Ribas Junior et. al. (2004), the above occurs when the influence of social desirability is involuntary, or rather, the respondent is not aware of a biased answer. A variation of social desirability is image management that occurs when the respondent manipulates the answer on purpose and thus the personal image transmitted is controlled.

The requirement to know and assess social desirability is because the variable may jeopardize the validity and reliability of psychological and behavior research (Ribas Junior et. al., 2004). Consequently, several social desirability measurement scales have been recently prepared.

Thus, it was sought to assess consumer behavior in two ways to respond to the assertions of the scale: How the individual responds about your attitude and how he observes the attitude of people in society with the purpose of evaluating whether the responses showed social desirability. 


\subsection{Methodology}

Current research evaluates consumer's purchase intentions green products in supermarket retail, compares results on their self-evaluation and the manner they observe the attitude of people in society. A survey was conducted on a sample of 811 consumers in retail supermarket in three Brazilian cities: Sao Paulo/SP, Curitiba/PR, and Rio de Janeiro/RJ to evaluate the following hypotheses:

H1. The individual's environmental concern is transformed into purchase intent;

$\mathrm{H} 2$. The individual's purchase intent is transformed into declared purchase for green products;

$\mathrm{H} 3$. The individual's environmental concern is transformed into declared purchase;

H4. The individual's environmental concern making realize the purchase intention of the other;

H5. Purchase intent attributed to others is transformed into declared purchase attributed to others;

H6. The individual's environmental concern does he realize the declared purchase attributed to others.

Validated scale contained 17 items on Environmental Concern, 13 on Declared Purchase and 15 on Purchase Intention (table 1). For application was used Likert-like scales with five agreement and disagreement points were employed in which 1 meant total disagreement and 5 meant total agreement.

For the column YOU, participants were asked to give score 1 to 5 for statements to which they disagreed or agreed. For column OTHERS, participants were asked to give score 1 to 5 when it is believed that other people (society) would disagree or agree with each statement.

SPSS 15.0 was used for data analysis of frequency tests and Smart PLS 2.0 - M3 was employed to evaluate structural equations modeling (SEM) (Ringle, Wende \& Will, 2005). SEM was employed as the main method for data analysis. In fact, the model evaluates the causal relationships between the constructs and the subsequent hypotheses test by evaluating past coefficients.

Measure model Partial Least Square - Path Modeling (PLS-PM) was employed. When Mardia PK test of adherence to a normal multivariate distribution was undertaken (Hair et. al., 2013), it was significant $(p<0.001)$. Consequently, data from matrix variables failed to comply with the desired multivariate distribution.

Measurement models for SEM calculation were those with Free Asymptotic Distribution, or rather, the non-necessity of multivariate normality. Three models may be used: Diagonally Weighted Least Square (DWLS), Weighted Least Square (WLS) and PLS-PM. (Hair et. al., 2013). The first two require extensive samples, or rather, at least, double that obtained in current research. They were disposed of. PLS-PM was an adequate possibility for data analysis. PLS-PM is a quality alternative proven by the international research community in several areas of knowledge (Ringle, Wende \& Will, 2005), with great flexibility in data analysis. 
Table 1. Scales used in research

\begin{tabular}{|c|c|c|}
\hline Construct & Lab & Items \\
\hline \multirow{16}{*}{ 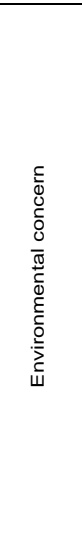 } & EC_1 & Firms that damage or disrespect the environment should be punished. \\
\hline & EC_2 & Agricultural toxics and dangerous substances in food harm the environment. \\
\hline & EC_3 & I understand that organic products do not impact the environment \\
\hline & EC_4 & Environmental declarations demonstrate that the manufacturer may have concern with the environment. \\
\hline & EC_5 & I am concerned with pollution in my town \\
\hline & EC_6 & I am worried when I see people dirtying streets and parks \\
\hline & EC_7 & I separate recyclable wastes from organic residues at home \\
\hline & EC_8 & Deforesting may place the future of humanity at risk \\
\hline & EC_9 & I prefer public transport or bike riding \\
\hline & EC_10 & I feel that I may help solve the problem of natural resources by saving water and energy \\
\hline & EC_11 & I feel I may protect the environment by buying ecologically correct products \\
\hline & EC_12 & The emission of carbon dioxide damages the atmosphere \\
\hline & EC_13 & Plastic and paper bags destroy natural resources \\
\hline & EC_14 & Plastic and paper bags should be recycled and not deposited in the environment. \\
\hline & EC_15 & Home chemical products (detergents and cleaning products) damage the environment after use \\
\hline & EC_16 & I try to reuse wrappings when possible \\
\hline \multirow{15}{*}{ 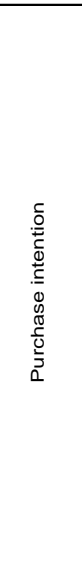 } & PI_1 & When possible I choose products which cause the least pollution possible. \\
\hline & PI_2 & I avoid manufactured products that damage or disrespect the environment. \\
\hline & PI_3 & I buy food without agricultural toxic products since the environment is respected. \\
\hline & PI_4 & $\begin{array}{l}\text { I pay a somewhat higher price for products and food free of chemical substances which damage the } \\
\text { environment. }\end{array}$ \\
\hline & PI_5 & Difference in price interferes in my intention in buying ecologically correct products. \\
\hline & PI_6 & I may pay more to buy organic products since they do not impact the environment \\
\hline & PI_7 & I may prefer products with information on the manufacturers' environmental certificates. \\
\hline & PI_8 & I verify whether a product that I intend to buy does not damage the environment or other people \\
\hline & PI_9 & I am decided to buy concentrated products \\
\hline & PI_10 & I am decided to buy compacted products to reduce gas emission into the atmosphere \\
\hline & PI_11 & I am decided to buy products with scanty wrappings to reduce the consumption of natural resources \\
\hline & PI_12 & I am decided to avoid buying products with non-biodegradable wrappings. \\
\hline & PI_13 & $\begin{array}{l}\text { I am decided to buy home chemical products (detergents and cleaning products) which are ecologically correct } \\
\text { or biodegradable }\end{array}$ \\
\hline & PI_14 & I am decided to buy refill products so that the previous wrapping need not be disposed of \\
\hline & PI_15 & I am decided to buy some products (currently bought in smaller sizes) in bigger sizes and with less frequency \\
\hline \multirow{14}{*}{$\begin{array}{l}0 \\
0 \\
0 \\
\frac{0}{0} \\
0 \\
\vdots \\
0 \\
0 \\
0 \\
\frac{0}{0} \\
\frac{\pi}{0} \\
0\end{array}$} & DP_1 & When I buy a product I always verify whether the manufacturing firms damage or disrespect the environment. \\
\hline & DP_2 & I always buy food without any agricultural toxins since I am aware that I am preserving the environment. \\
\hline & DP_3 & I pay more to buy products that promote the protection of the environment \\
\hline & DP_4 & I buy organic products because they are healthier. \\
\hline & DP_5 & I pay more to buy organic products since they are healthier. \\
\hline & DP_6 & I buy products with environmental certificates since they are ecologically correct. \\
\hline & DP_7 & $\begin{array}{l}\text { I always choose a product which causes the least damage to people and to the environment when choosing } \\
\text { between two competitive products. }\end{array}$ \\
\hline & DP_8 & I always buy concentrated products since they may save water and energy \\
\hline & DP_9 & I buy compacted products to contribute for the decrease in gas emissions and their transport is easier \\
\hline & DP_10 & I always buy products with the least wrappings possible \\
\hline & DP_11 & I always buy ecologically correct or biodegradable home chemicals (detergents and cleaning products) \\
\hline & DP_12 & I buy refill products to take advantage of the previous wrapping \\
\hline & DP_13 & I always buy products with non-traditional packing design since less solid wastes may be produced. \\
\hline & DP_14 & I switched or did not use anymore products because of ecological motives. \\
\hline
\end{tabular}




\subsection{Results And Discussions}

As was discussed for the analysis of the data was used Smart PLS 2.0 M3 software. Departing from the original model with all items of the scale, the model was tested and corrected by removing items that did not have a factor loading above 0.50 (Hair et. al., 2013) and impair the adjustment of the model and its validity statistics.

Even so, the averages, standard deviations and coefficients of variation of the responses provided by the individuals of the sample collected for discarded items. Thus, there has been a very low variability (most showed a constant response or disagreement within the same issue without presenting a possible variability analysis).

The $R^{2}$ evaluates a part of the variables that explain the constructs and indicates the quality of the adjustment model. Values of $0.75,0.50$ and 0.25 are considered significant, moderate and weak, respectively (Hair et. al., 2013). Average Variance Extracted (AVE) should be greater than 0.50 to satisfy the convergence of the model. Already Cronbrach's alpha (internal consistency) and Composite Reliability is used to assessing whether the sample is free of bias, or if the answers as a whole, are reliable.

The Communality (f2) evaluates how each construct is "useful" to the model adjustment. Values of $0.02,0.15$ and 0.35 are considered small, medium and large, respectively, and Redundancy (Q2) evaluates the accuracy of the adjustment model. The evaluation criteria are greater than zero (Hair et. al., 2014) values. After those adjustments, the average variance extracted (AVE), composite reliability, Cronbach's alpha and R2, Communality (f2) and Redundancy (Q2) of the constructs were assessed to analyze how the model was measured, as shown in Table 2.

Table 2. Quality criteria of model adjustments - SEM specification - Average Variance Extracted (AVE), Composite Reliability, R2, Cronbach's Alpha, Redundancy and Communality

\begin{tabular}{|c|c|c|c|c|c|c|}
\hline & AVE & $\begin{array}{l}\text { Composite } \\
\text { Reliability }\end{array}$ & R Square & $\begin{array}{l}\text { Cronbach's } \\
\text { Alpha }\end{array}$ & Redundancy & Communality \\
\hline DP_Ind & 0,511349 & 0,893248 & 0,408761 & 0,863878 & 0,200363 & 0,373152 \\
\hline DP_Other & 0,527591 & 0,869925 & 0,323307 & 0,820418 & 0,160964 & 0,327942 \\
\hline EC_Ind & 0,55498 & 0,918076 & & 0,899902 & 0,436833 & 0,436833 \\
\hline IP_Ind & 0,521184 & 0,883828 & 0,514629 & 0,846564 & 0,257748 & 0,350896 \\
\hline IP_Other & 0,527084 & 0,847779 & 0,129625 & 0,775651 & 0,06523 & 0,292177 \\
\hline $\begin{array}{l}\text { Reference } \\
\text { Value }\end{array}$ & $>0,50$ & $>0,70$ & $\begin{array}{l}0.02 \text { as } \\
\text { small, } \\
0.13 \text { as } \\
\text { medium, } \\
\text { and } 0.26 \\
\text { as large }\end{array}$ & $>0,60$ & Positive & Positive \\
\hline
\end{tabular}

Following the discriminant validity that the criterion of Fornell-Larcker, compares the square roots of the AVE values for each construct with the correlations (Pearson) between the constructs (or latent variables) was performed. The square roots of AVE's must be greater than the correlations between constructs. Discriminant validity indicates the extent to which constructs or latent variables are independent of one another (Hair et. al., 2014), as shown in Table 3. 
Braga Junior, S.S., et.al. / Asian Journal of Behavioural Studies (AjBeS), 3(12) Jul / Aug 2018 (p. 183-193)

Table 3. Comparison of the square roots of the AVE (in gray on the main diagonal) versus correlation between constructs

\begin{tabular}{llllll}
\hline & DP_Ind & DP_Other & EC_Ind & IP_Ind & IP_Other \\
\hline DP_Ind & 0,715086708 & & & & \\
DP_Other & 0,638885 & 0,726354597 & & & \\
EC_Ind & 0,430985 & 0,178868 & 0,744969798 & & \\
IP_Ind & 0,638183 & 0,338611 & 0,717376 & 0,721930745 & \\
IP_Other & 0,419288 & 0,567938 & 0,360035 & 0,526907 & 0,72600551 \\
\hline
\end{tabular}

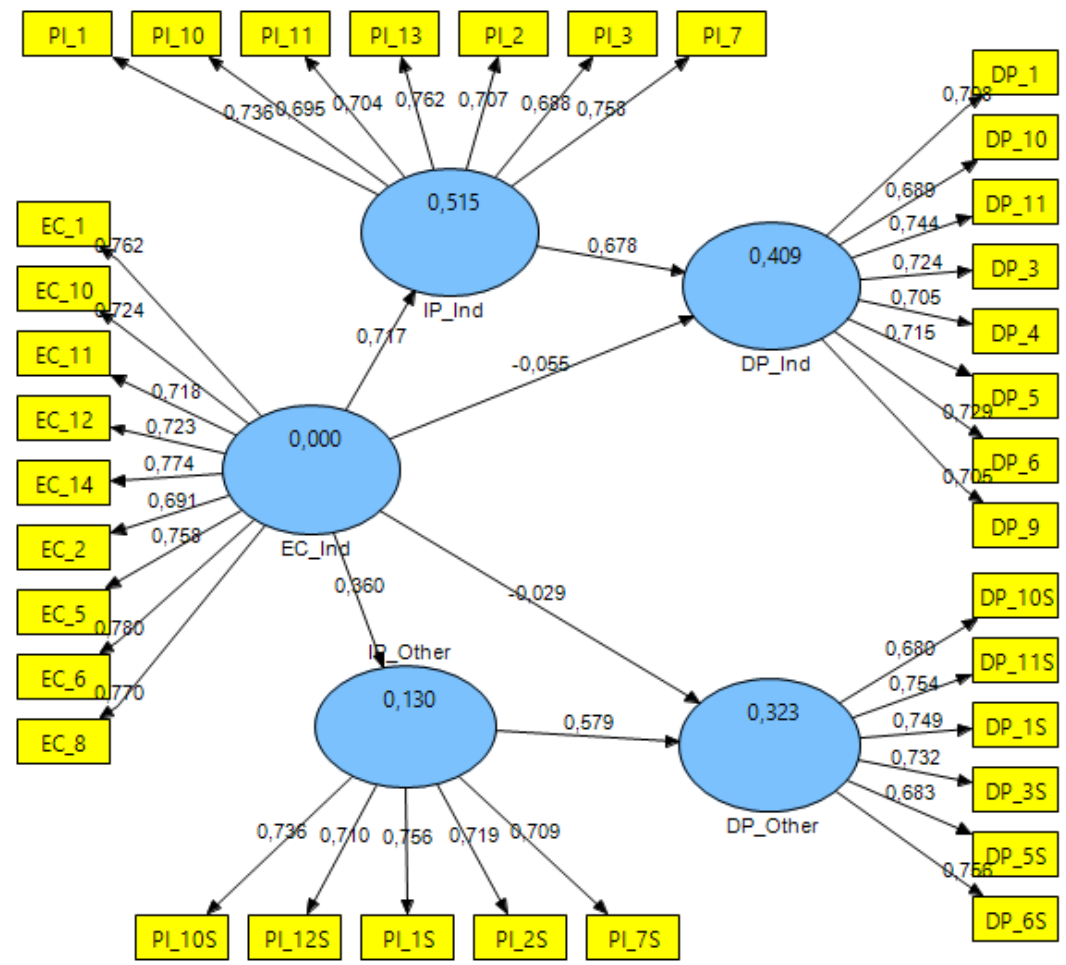

Fig. 1. Model adjusted in research

Note: All structural coefficients were significant $(p<0.05)$. Significance was estimated by bootstrap method with $\mathrm{N}=600$ and 1000 replications (RINGLE, WENDE \& WILL, 2005)

Nevertheless, still aiming to assess the overall quality of the adjustment model GoF indicator (Goodness-of-Fit) was calculated, which is given by the geometric mean of the average $R^{2}$ and average AVE (Ringle, Wende \& Will, 2005). The calculated value was 0.426 , 
indicated that the model was well adjusted, since values above 0.36 are considered good for areas such as social and behavioral sciences (Hair et. al., 2013).

Inserted all the indicators in each of their respective constructs and made the appropriate statistical adjustments, Figure 1 presents the model generated by the research, and that is the perception of individuals as to the effect of environmental concern in their purchase intent and purchase later declared, and the same individual observes the behavior of other people in society.

In this model, it is possible to observe that the intention to purchase green products is influenced by the environmental concern of the individual. This is also confirmed when analyzing the model looking as it was this same relationship when the individual responds on their perception of how others behave.

The relationship between environmental concerns and declared purchase this situation is not confirmed when the individual is asked about his behavior and how others behave. This does not mean that the behavior does not happen, it demonstrates to the buying behavior happen the individual must have the intention to buy.

Thus, once confirmed the quality of the model promoted adjustments, was able to make inferences about the path coefficients and the $p$-value of each relationship, taken from Figure 1 , as being the adjusted model, these values can be used to evaluate the research hypotheses, as shown in Table 4. As the conclusion of the hypotheses, unsupported prove it by the fact that present a $p>0.05$.

Table 4. Evaluation of hypotheses

\begin{tabular}{llll}
\hline & $\beta$ & $p$-valor & Conclusion \\
\hline EC_Ind $=>$ DP_Ind & $-0,055282$ & 0,041512 & Not supported \\
EC_Ind $=>$ DP_Other & $-0,029424$ & 0,033161 & Not supported \\
EC_Ind $=>$ IP_Ind & 0,717376 & 0,023261 & Supported \\
EC_Ind $=>$ IP_Other & 0,360035 & 0,038111 & Supported \\
IP_Ind $=>$ DP_Ind & 0,677841 & 0,042968 & Supported \\
IP_Other => DP_Other & 0,578532 & 0,038298 & Supported \\
\hline Reference Value & Positive & $<0,05$ & ----- \\
\hline
\end{tabular}

\subsection{Conclusions}

Often the buying decision taken by an individual is not the one desired by him, but the decision that best suits your need at the time and reality. On the other hand, a society to which it is inserted does not generate conditions of adaptation and charges a posture that is not yet part of your reality.

Assess the consumer's perception of an aspect of purchase intent and declared to purchase green products, it becomes relevant, especially when the reflection of environmental concern in the declared purchase not established. 
Thus, considering the purpose of the research, it can be inferred that environmental concern has no effect on the declared purchase for green products. On the other hand, has a significant relationship with the intention of purchase.

These inferences can be justified by the possibility of consumers do not realize the importance of changing the habit of consumption and keep their shopping routine that has past experience, reinforcing the fact that the attitude to have a low influence on the buying behavior of the individual, as already demonstrated Bagozzi (1981). In this sense, research has shown that environmental concern reflects the intention to purchase and should be the focus of study to transform the attitude behavior.

Moreover, the results demonstrate the fact that opinion correct path, but suffer from the influence of politically correct answers and end up hurting future developments in new research because it is a sense that consumers are realizing what was searched.

Otherwise, the results of the responses between the individual performed and what he observes in society should be nearly equal, because everyone in society. Another aspect that may not be contributing to the increased supply of green products in retail can be connected to the positioning of marketing.

Another point of view to be reflected may be the possibility of consumers are seeking organic or environmentally friendly in specialized retails these products, making conventional supermarkets do not worry about investing and making this product in their stores, opening thus a search field.

Finally, the main contribution of the study to the gym was to prove that the consumer is still buying green products considerably, but there is this trend drawn that possibly still restricted on price and consumption habit.

\section{Acknowledgement}

The National Council for Scientific and Technological Development (CNPq) for financial support to the survey. Foundation for Research of the State of Sao Paulo - FAPESP for financial support to the survey.

\section{References}

Ajzen, I. (2001). Nature and Operation of Attitudes.Annual Reviews Psychol. v. 52, p. 27-58.

Ar, I. M. (2012). The Impact of Green Product Innovation on Firm Performance and Competitive Capability: The Moderating Role of Managerial Environmental Concern. Procedia-Social and Behavioral Sciences, 62, 854-864.

Bagozzi, Richard P. (1981). Attitudes, intentions, and behavior: A test of some key hypotheses. Journal of Personality and Social Psychology, Vol 41(4), 607-627. doi: 10.1037/0022-3514.41.4.607

Braga Junior, S. S., \& da Silva, D. (2013). A Relação da Preocupação Ambiental com Compra Declarada para Produtos Verdes no Varejo: Uma Comparação da Percepção do Individuo com sua Percepção de Sociedade. Perspectivas em Gestão \& Conhecimento, 3(2), 161-176. 
Braga Junior, S. S., da Silva, D., Satolo, E. G., Magalhães, M. M., Putti, F. F., \& de Oliveira Braga, W. R. (2014). Environmental concern has to do with the stated purchase behavior of green products at retail?. Social Sciences, 3(1), 23-30. doi: 10.11648/j.ss.20140301.15

Crumpei, I., Boncu, S., \& Crumpei, G. (2014). Environmental Attitudes and Ecological Moral Reasoning in Romanian Students. Procedia-Social and Behavioral Sciences, 114, 461-465.

Hair Jr, J. F., Hult, G. T. M., Ringle, C., \& Sarstedt, M. (2013). A primer on partial least squares structural equation modeling (PLS-SEM). SAGE Publications, Incorporated.

Jamaluddin, M. R., Hanafiah, M. H., \& Zulkifly, M. I. (2013). Customer-based Psychology Branding. Procedia-Social and Behavioral Sciences, 105, 772-780.

Manuela, V. Z., Manuel, P. R., Murgado-Armenteros Eva, M., \& José, T. R. F. (2013). The Influence of the Term 'Organic'on Organic Food Purchasing Behavior. Procedia-Social and Behavioral Sciences, 81, 660-671.

Ozguven, N. (2012). Organic foods motivations factors for consumers.Procedia-Social and Behavioral Sciences, 62, $661-665$.

Poínhos, R., Correia, F., Faneca, M., Ferreira, J., Gonçalves, C., Pinhão, S, \& Medina, J.L. (2008). Desejabilidade Social E Barreiras Ao Cumprimento Da Terapêutica Dietética Em Mulheres Com Excesso De Peso. Acta Med Port, v. 21: $221-228$.

RahimOf, F. (2011). Effects of Educational Improvements on Student Social Desirability. Procedia-Social and Behavioral Sciences, 29, 932-935.

Ribas Junior, R.C., \& Seidl-de-Moura, M.L. (2004). Adaptação brasileira da Escala de Desejabilidade Social de Marlowe-Crowne. Avaliação Psicológica, 3(2), pp. 83-92.

Ringle, C.M., Wende, S., \& Will, A. (2010). SmartPLS 2.0 M3 (beta). Germany: Universityof Hamburg, 2005. Available at on 18 Nov 2010.

Sârbescu, P., Costea, I., \& Rusu, S. (2012). Psychometric properties of the Marlowe-Crowne Social Desirability Scale in a Romanian sample. Procedia-Social and Behavioral Sciences, 33, 707-711.

Tai, C. L., Hong, J. Y., Chang, C. M., \& Chen, L. C. (2012). Determinants of Consumer's Intention to Participate in Group Buying. Procedia-Social and Behavioral Sciences, 57, 396-403.

Yildirim, Y., \& Aydin, O. (2012). Investigation of the Effects of discount Announcements on Consumers' Purchase decisions: A Case Study in Supermarket. Procedia-Social and Behavioral Sciences, 62, 1235-1244. 